\title{
A meta-analysis of association between C677T polymorphism in the methylenetetrahydrofolate reductase gene and hypertension
}

\author{
Xueqing Qian ${ }^{1,2,5}$, Zhigang Lu ${ }^{3,5}$, Miao Tan ${ }^{4}$, Hongliang $\mathrm{Liu}^{1}$ and Daru Lu*,1
}

\begin{abstract}
${ }^{1}$ State Key Laboratory of Genetic Engineering, Institute of Genetics, School of Life Sciences, Fudan University, Shanghai, PR China; ${ }^{2}$ Shanghai Zhujian Bio-engineering Company, Ltd, Shanghai, PR China; ${ }^{3}$ Department of Cardiology, Shanghai 6th Hospital, Shanghai, PR China; ${ }^{4}$ Shanghai Research Center for Life Science, SIBS, Chinese Academy of Sciences, Shanghai, PR China
\end{abstract}

The C677T polymorphism of the methylenetetrahydrofolate reductase (MTHFR) gene was implicated to be associated with hypertension due to its role in catalyzing the formation of 5-methylenetetrahydrofolate, a co-substrate for the conversion of homocysteine to methionine. Association studies were reported in different populations; however, a great number of subsequent studies have produced contrary results, possibly reflecting inadequate statistical power. With the cumulative data in recent years in both Caucasian and Asian populations, it was necessary to carry out a comprehensive analysis of previous findings. In this meta-analysis, we combined 26 English and Chinese studies in Caucasian and Asian populations published up to November 2006 to give a new picture of the role of the C677T polymorphism in the MTHFR gene. Evidence of significant association was detected between C677T polymorphism and hypertension in both populations. Additionally, the significant association between C677T polymorphism and hypertension/ hypertension-in-pregnancy suggested that this polymorphism was one independent risk factor of hypertension.

European Journal of Human Genetics (2007) 15, 1239-1245; doi:10.1038/sj.ejhg.5201914; published online 29 August 2007

Keywords: MTHFR; meta-analysis; OR; heterogeneity; publication bias

\section{Introduction}

The development of hypertension is believed to be largely under genetic control. ${ }^{1}$ A considerable number of genes and polymorphisms thereof have been assessed as candidate determinants of the risk for hypertension. ${ }^{2}$ Many case-control studies have addressed in particular the putative role of a C-to-T mutation at nucleotide 677 in the methylenetetrahydrofolate reductase (MTHFR) gene.

\footnotetext{
*Correspondence: Professor D Lu, State Key Laboratory of Genetic Engineering, Institute of Genetics, School of Life Sciences, Fudan University, Room 5014, Yichuan Building, 220 Handan Road, Shanghai 200433, PR China. Tel and Fax: + 8621 65642799;

E-mail: drlu@fudan.edu.cn

${ }^{5}$ These two authors contributed equally to this work

Received 24 January 2007; revised 24 May 2007; accepted 27 July 2007; published online 29 August 2007
}

MTHFR catalyzes the formation of 5-methylenetetrahydrofolate, a co-substrate for the conversion of homocysteine to methionine. ${ }^{3-5}$ The $\mathrm{T}$ allele has been associated in its homozygous form with elevated homocysteine through the creation of a thermolabile enzyme isoform with reduced activity, ${ }^{6}$ and a high plasma concentration of homocysteine may predispose to atherosclerosis by injuring the vascular endothelium, which results in hypertension. ${ }^{7}$ The genotype frequencies of the polymorphism are C/C, 0.583; C/T, 0.35; T/T, 0.067 in Europeans and C/C, $0.267 ; \mathrm{C} / \mathrm{T}, 0.444 ; \mathrm{T} / \mathrm{T}, 0.289$ in Chinese (www.hapmap.org). A number of population studies provided 'positive' and 'negative' results in both hypertension and hypertension-in-pregnancy. However, the results of the genetic association studies on the role of the C677T MTHFR polymorphism in hypertension have generated 
considerable controversy. ${ }^{8,9}$ Given the accumulation of data, we decided to perform a formal meta-analysis to reconcile the conflicting findings.

\section{Methods}

\section{Literature search}

The literature included in the analysis was selected using PubMed and CNKI (Chinese) with keywords 'methylenetetrahydrofolate reductase' or 'MTHFR' and 'hypertension'. The search was complemented with a perusal of the bibliographies of retrieved papers and review articles. Eligible studies had to meet all of the following criteria: (1) they were published in a peer-reviewed journal, (2) they contained independent data, (3) they presented sufficient data to calculate the odds ratio (OR) with a confidence interval and a $P$-value, (4) they were association studies, (5) they described the relevant genotyping primers, machines and protocols or provided reference to them, (6) they diagnosed patients according to the criteria of $S B P \geq 140$ or $\mathrm{DBP} \geq 90$ and (7) they used healthy individuals as controls. Authors were contacted in cases where there were queries regarding their studies.

\section{Statistical analyses}

Data from the case-control studies were used to construct a $2 \times 2$ table in which subjects were classified by diagnostic category and type of allele. Cochran's $\chi^{2}$-based $Q$ statistic test was performed in order to assess possible heterogeneity in the combined studies. Where heterogeneity existed, the random effects model, which yields wider confidence intervals (CIs), was adopted; otherwise both the fixed effects and random effects models were deemed appropriate. A test for funnel plot asymmetry, described by Egger et al, ${ }^{10}$ was used to assess evidence for publication bias. ORs were pooled using the DerSimonian and Laird ${ }^{11}$ method and $95 \%$ CIs were constructed using Woolf's ${ }^{12}$ method. The significance of the overall OR was determined by the $Z$-test. The analysis was conducted on Comprehensive Meta Analysis software (Version1.0.23, BIOSTAT, Englewood, NJ, USA).

\section{Results}

The combined search yielded at least 167 references. After discarding overlapping references and those that clearly did not meet the criteria, 26 studies were identified ${ }^{13-39}$ for recruitment. Of these, 13 were case-control studies on the association of C667T polymorphism in the MTHFR gene and hypertension in pregnancy. All studies were published between 1998 and 2006. The descriptive characteristics of all the 26 studies included in our meta-analytic study were coded using the following variables: the first author (year of publication), the ancestry of the sample, the year of

Table 1 Characteristics of the included studies

\begin{tabular}{|c|c|c|c|c|}
\hline First author (year) & Ancestry & Enrollment & Cases/controls & Diagnostic standard \\
\hline \multicolumn{5}{|l|}{ Hypertension } \\
\hline Yukiko Nakata (1998) & Japanese & 1992-1995 & $173 / 184$ & $S B P \geq 160, D B P \geq 95$ \\
\hline Siyan Zhan (2000) & Chinese & $1997-2001$ & $127 / 170$ & $S B P \geq 140, D B P \geq 90$ \\
\hline Petr Benes (2001) & Caucasian & $1996-2000$ & $193 / 209$ & $S B P \geq 140, D B P \geq 90$ \\
\hline Lin Wang (2002) & Chinese & $2000-2001$ & $105 / 46$ & $S B P \geq 140, D B P \geq 90$ \\
\hline Xiaonan Sun (2003) & Chinese & No data & $55 / 46$ & $S B P \geq 140, D B P \geq 90$ \\
\hline Stephanie HEUX (2004) & Caucasian & No data & $247 / 249$ & $S B P \geq 140, D B P \geq 90$ \\
\hline Jianwei Liu (2004) & Chinese & No data & $159 / 100$ & $S B P \geq 140, D B P \geq 90$ \\
\hline Leszek Tylicki (2005) & Austrian/Polish & $2002-2003$ & $90 / 90$ & $S B P \geq 140, D B P \geq 90$ \\
\hline Rile Hu (2006) & Mongolian & No data & $110 / 115$ & $S B P \geq 140, D B P \geq 90$ \\
\hline Htay Lwin (2006) & Japanese & $1999-2000$ & $116 / 219$ & $S B P \geq 140, D B P \geq 90$ \\
\hline B Nagy (2006) & Hungarian & $2000-2005$ & $101 / 73$ & $S B P \geq 160, D B P \geq 90$ \\
\hline Xiuxiu Li (2006) & Chinese & 2003 & $72 / 30$ & No data \\
\hline \multicolumn{5}{|l|}{ Hypertension in pregnancy } \\
\hline Robert W Powers (1999) & Caucasian & No data & $123 / 114$ & $S B P \geq 140, D B P \geq 90$ \\
\hline Elvira Grandone (1999) & Caucasian & No data & $139 / 216$ & $S B P \geq 140, D B P \geq 90$ \\
\hline Keshen Li (2000) & Chinese & No data & $62 / 90$ & $S B P \geq 140, D B P \geq 90$ \\
\hline Gen Kobashi (2000) & Japanese & No data & $174 / 215$ & $S B P \geq 140, D B P \geq 90$ \\
\hline Shuqing Wei (2001) & Chinese & $1999-2000$ & $42 / 36$ & $\mathrm{SBP} \geq 140, \mathrm{DBP} \geq 90$ \\
\hline Feng Fu (2003) & Chinese & $2001-2002$ & $102 / 100$ & $S B P \geq 140, D B P \geq 90$ \\
\hline Hulya Yilmaz (2004) & Turkish & No data & $64 / 47$ & $S B P \geq 140, D B P \geq 90$ \\
\hline Haiyan Wang (2004) & Chinese & $2000-2003$ & $99 / 54$ & $S B P \geq 140, D B P \geq 90$ \\
\hline Dongwei Mao (2004) & Chinese & $1998-2002$ & $100 / 100$ & $S B P \geq 140, D B P \geq 90$ \\
\hline Geng Tian (2005) & Chinese & $2003-2004$ & $61 / 56$ & no data \\
\hline Sonia Hernandez-Diaz (2005) & Caucasian & $1993-1998$ & $54 / 100$ & $S B P \geq 140, D B P \geq 90$ \\
\hline Sumin Wang (2006) & Chinese & $2002-2004$ & $54 / 125$ & $S B P \geq 140, D B P \geq 90$ \\
\hline Gen Kobashi (2006) & Japanese & $1993-1998$ & $100 / 100$ & $S B P \geq 140, D B P \geq 90$ \\
\hline
\end{tabular}


sample enrolment, the size of design and the diagnostic standard of each study (Table 1).

MTHFR C677T TT genotype and risk for hypertension Global statistical results of the 25 case-control association studies (data not sufficient in one study ${ }^{37}$ ) of the C677T genotype TT of the MTHFR gene and hypertension, only five ${ }^{15,19,24,25,34}$ showed a statistically significant difference in allele frequencies between hypertensive and control subjects (see Figure 1a). The pooled OR derived from 2814 hypertensive and 3099 control subjects in 25 recruited studies was statistically significant (see Table 2). Homogeneity analysis for the ORs from the 25 studies of the genotype TT suggested that there was statistically significant evidence for heterogeneity of the ORs among the groups of genotype TT studies (see Table 2). There was no significant evidence of publication bias detected in the total studies (Table 2 and Figure 2a).
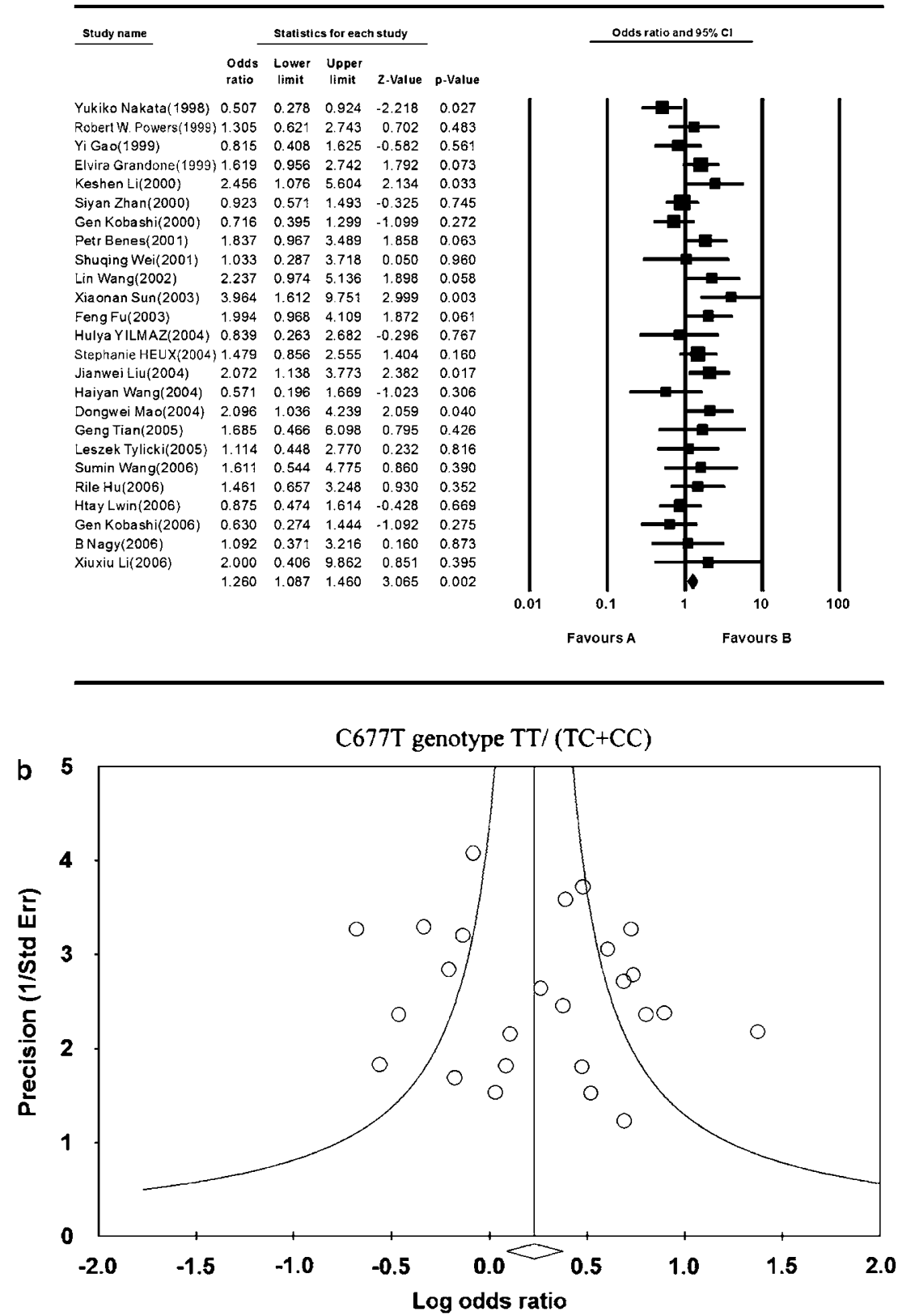

Figure $1(\mathbf{a}, \mathbf{b})$ Forest plots of In (OR) with $95 \% \mathrm{Cl}$ for studies with hypertension. Black squares indicate the In (OR), with the size of the square inversely proportional to its variance, and horizontal lines represent the $95 \% \mathrm{Cls}$. The pooled results are indicated by the unshaded black diamond. 
Table 2 Basic statistical data of MTHFR polymorphism and risk for hypertension

\begin{tabular}{|c|c|c|c|c|}
\hline \multirow[b]{2}{*}{ Group } & \multicolumn{2}{|c|}{$T T /(T C+C C)$} & \multirow{2}{*}{\multicolumn{2}{|c|}{$\begin{array}{l}(T T+T C) / C C \\
\text { Pooled OR }\end{array}$}} \\
\hline & Heterogeneity & Pooled OR & & \\
\hline HP & $\begin{array}{l}Q=16.075 \\
\mathrm{df}=11, P=0.138\end{array}$ & $\begin{array}{l}\mathrm{OR}=1.282,95 \% \\
\mathrm{Cl}=0.959-1.714 \\
Z=1.679, P=0.093 \\
\text { random }\end{array}$ & $\begin{array}{l}Q=24.060 \\
d f=11, P=0.012\end{array}$ & $\begin{array}{l}\mathrm{OR}=1.661,95 \% \mathrm{Cl}=1.387-1.989 \\
Z=5.515, P<0.001, \text { random }\end{array}$ \\
\hline $\mathrm{H}$ & $\begin{array}{l}Q=26.25, \mathrm{df}=12 \\
P=0.010\end{array}$ & $\begin{array}{l}\mathrm{OR}=1.235,95 \% \\
\mathrm{Cl}=1.020-1.497 \\
z=2.158, P=0.031 \\
\text { fixed }\end{array}$ & $\begin{array}{l}Q=13.833 \\
\mathrm{df}=12, P=0.312\end{array}$ & $\begin{array}{l}\mathrm{OR}=1.165,95 \% \mathrm{Cl}=1.006-1.350 \\
z=2.034, P=0.042, \text { fixed }\end{array}$ \\
\hline Asian & $\begin{array}{l}Q=38.866 \\
\mathrm{df}=17, P=0.002\end{array}$ & $\begin{array}{l}\mathrm{OR}=1.189,95 \% \\
\mathrm{Cl}=0.996-1.419 \\
Z=1.913, P=0.056 \\
\text { random }\end{array}$ & $\begin{array}{l}Q=42.391 \\
\mathrm{df}=17, P=0.001\end{array}$ & $\begin{array}{l}\mathrm{OR}=1.403,95 \% \mathrm{Cl}=1.218-1.617 \\
z=4.681, P<0.001, \text { random }\end{array}$ \\
\hline Total & $\begin{array}{l}Q=42.427 \\
\mathrm{df}=24, P=0.012\end{array}$ & $\begin{array}{l}\mathrm{OR}=1.260,95 \% \\
\mathrm{Cl}=1.087-1.460 \\
z=3.065, P=0.002 \\
\text { random }\end{array}$ & $\begin{array}{l}Q=46.792 \\
\mathrm{df}=24, P=0.004\end{array}$ & $\begin{array}{l}\mathrm{OR}=1.416,95 \% \mathrm{Cl}=1.200-1.670 \\
Z=4.118, P<0.001, \text { random }\end{array}$ \\
\hline $\begin{array}{l}\text { Total } \\
\text { publication bias }\end{array}$ & $\begin{array}{l}a=0.614(95 \% \mathrm{Cl} \\
\mathrm{df}=23, P=0.529\end{array}$ & $1.375-2.604), t=0.639$ & $\begin{array}{l}a=2.773(95 \% \mathrm{Cl} \\
P=0.006\end{array}$ & $853-4.693), t=2.988, \mathrm{df}=23$ \\
\hline
\end{tabular}

$\mathrm{HP}$, hypertension in pregnancy; $\mathrm{H}$, hypertension; Asian, Asian studies; Caucasian, Caucasian studies. Chinese, Japanese and Mongolian studies in this analysis were defined as Asian and the rest as Caucasian.

\section{Significance tests of ORs between the groups}

Hypertension-in-pregnancy studies and hypertension studies $(z=3.065, P=0.002) \quad$ No significant heterogeneity was observed after stratification of the group of ORs by sample constitution in 12 hypertension-in-pregnancy studies, but it remained in 13 hypertension studies. The pooled ORs for the studies of the genotype TT derived from hypertension samples showed statistical significance but were not present among hypertension-in-pregnancy studies (Table 2).

Studies in different populations $(z=3.065, P=0.002)$ No significant heterogeneity was observed after stratification of the group of ORs by sample constitution in seven studies in Caucasians, but it remained in 18 studies in Asians. The pooled ORs for the studies of the genotype TT derived from western studies showed statistical significance but were not present among studies in Asians (Table 2).

MTHFR C677T T carriers and risk for hypertension Global statistical results of the 25 case-control association studies of the C677T allele T carriers of the MTHFR gene and hypertension, $\operatorname{six}^{9,15,16,19,24,26}$ showed a statistically significant difference in allele frequencies between hypertensive and control subjects (data not sufficient in one study ${ }^{39}$ ) (see Figure 1b). The pooled OR derived from 2814 hypertensive and 3099 control subjects was statistically significant (see Table 2 ). Homogeneity analysis for the ORs from the 25 studies of the allele $\mathrm{T}$ carriers suggested that there was statistical significance evidence for heterogeneity of the ORs among the groups of allele T carriers' studies (see Table 2). There was significant evidence of publication bias detected in the total studies (Table 2 and Figure 2b).

\section{Significance tests of ORs between the groups}

Hypertension-in-pregnancy studies and hypertension studies $(Z=5.065, P<0.001) \quad$ No significant heterogeneity was observed after stratification of the group of ORs by sample constitution in $\mathrm{H}$ studies, but it remained in HP studies. The pooled ORs for the studies of the allele T derived from both $\mathrm{H}$ and HP studies showed statistical significance (Table 2).

Asian studies and Caucasian studies $(z=5.065, P<0.001)$ No significant heterogeneity was observed after stratification of the group of ORs by sample constitution in seven western studies, but it remained in 18 Asian studies. The pooled ORs for the studies of the allele $T$ derived from Caucasian and Asian studies showed statistical significance (Table 2). 
a
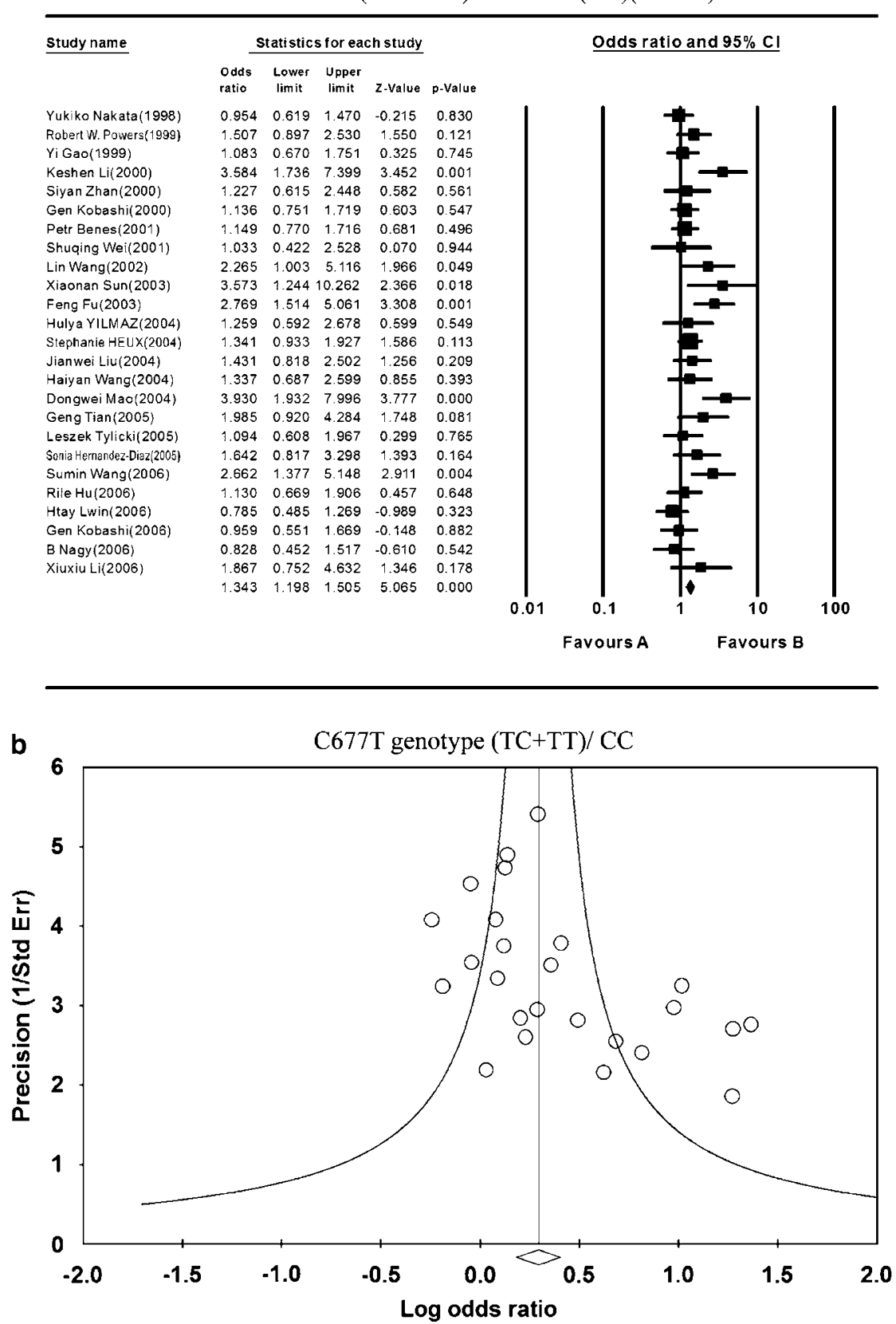

Figure 2 (a, b) Egger's funnel plots of publication bias analysis for studies with hypertension. The larger deviation from funnel curve of each study means the more pronounced asymmetry. Results from small studies will scatter widely at the bottom of the graph, with the spread narrowing among larger studies.

\section{Discussion}

Meta-analysis is a powerful tool for analyzing cumulative data of studies where the individual sample sizes are small and the statistical power low. This meta-analysis has included data for the C677T MTHFR polymorphism from over 2800 subjects who were hypertensive, along with a similar number of normotensive controls. We found an association of this polymorphism with hypertension and hypertension-in-pregnancy, but there was large and statistically significant heterogeneity in the results of different studies. This necessitated a number of subgroup and bias analyses that yielded some interesting findings. Significant heterogeneity for ORs was detected in eastern studies after subgroup analysis, which suggested that the analytic results from eastern samples may not be reliable. 
Time lag bias and publication bias may have affected these results. In time lag bias, ${ }^{40}$ studies with 'negative' results take longer time to be published, while enthusiastic results are published much more quickly. In publication bias, ${ }^{41,42}$ small studies with 'negative' results are never published, while equally small studies with similar quality but 'positive' results would appear in the literature. We examined these possibilities and found that, indeed, 'positive' studies were reported more in T allele carriers' studies (especially in eastern studies), which could explain the existence of bias. Other phenomena of bias were also observed in the subgroup analysis, which we ascribed to insufficiency for the studies after grouping.

Our study has advantages compared with the metaanalysis previously reported. ${ }^{43}$ We inspected not only hypertension but also hypertension-in-pregnancy and the accordant results suggested that the association between this polymorphism and vascular disease that increases the risk both for hypertension and hypertension in pregnancy may be seen only in the setting of hyperhomocysteinemia. ${ }^{44-46}$ Elevated levels of homocysteine may be correlated with hypertension and hypertension in pregnancy. ${ }^{47}$ Dietary parameters may be acting as effect modifiers in this genetic association and may cause heterogeneity in the observed genetic effects across studies. ${ }^{43}$

In all, our meta-analysis suggested significance association between MTHFR C677T polymorphism and hypertension. The heterogeneity of the ORs we have identified among the studies of eastern populations is a real problem. Further clarification using enlarged sample sizes and additional family-based TDT studies is essential. Our meta-analysis of the 26 available population-based casecontrol studies points to inadequate statistical power, differences in geographic or ethnic background and potential gene-environment interactions all contributing to difficulty in interpreting the results in previous studies.

\section{Acknowledgements}

We are very grateful and thank Dr David Li of the Department of Bioinformation, Rockefeller University and Dr Shengzheng Guo of the Department of Biochemistry, Hongkong University for guidance in statistical methods; and we thank Mr Weisheng Xie and Ms Yexuan He of Shanghai Zhujian Bio-engineering Company, Ltd who were also helpful in data collection. We also thank the anonymous reviewers for their suggestive comments.

\section{References}

1 O'Shaughnessy KM: The genetics of essential hypertension. $\mathrm{Br}$ J Clin Pharmacol 2001; 51: 5-11.

2 Agarwal A, Williams GH, Fisher ND: Genetics of human hypertension. Trends Endocrinol Metab 2005; 16: 127-133.

3 Risch N, Merikangas K: The future of genetic studies of complex human diseases. Science 1996; 273: 1516-1517.

4 Slager SL, Schaid DJ: Evaluation of candidate genes in casecontrol studies: a statistical method to account for related subjects. Am J Hum Genet 2001; 68: 1457-1462.
5 Nakayama T, Soma M, Haketa A et al: Haplotype analysis of the prostacyclin synthase gene and essential hypertension. Hypertens Res 2003; 26: 553-557.

6 Benjafield AV, Iwai N, Ishikawa K, Wang WY, Morris BJ: Overweight, but not hypertension, is associated with SAH polymorphisms in Caucasians with essential hypertension. Hypertens Res 2003; 26: 591-595.

7 Boushey CJ, Beresford SA, Omenn GS, Motulsky AG: A quantitative assessment of plasma homocysteine as a risk factor for vascular disease. Probable benefits of increasing folic acid intakes. JAMA 1995; 274: 1049-1057.

8 Perry IJ: Homocysteine, hypertension and stroke. J Hum Hypertens 1999; 13: 289-293.

9 Wald DS, Law M, Morris JK: Homocysteine and cardiovascular disease: evidence on causality from a meta-analysis. BMJ 2002; 325: 1202 .

10 Egger M, Davey Smith G, Schneider M, Minder C: Bias in meta-analysis detected by a simple, graphical test. BMJ 1997; 315: 629-634.

11 DerSimonian R, Laird N: Meta-analysis in clinical trials. Control Clin Trials 1986; 7: 177-188.

12 Woolf B: On estimating the relation between blood group and disease. Ann Hum Genet 1955; 19: 251-253.

13 Wang H, Li C, Wang Z, Yang F: Relationships between polymorphisms of angiotensin 2 converting enzyme and methylenetetrahydrofolate reductase genes and genetic susceptibility to pregnancy induced hypertension. Chin J Obstet Gynecol 2004; 39: $369-372$.

$14 \mathrm{Hu} \mathrm{R}$, Niu G, Zhao S et al: The association between gene polymorphisms of methylene tetrahydrofolate reductase and Mongolian patients with drimary hypertension. Chin J Hypertens 2006; 14: 274-276.

15 Sun X, Li Y, Guo H: The gene polymorphisms of homocysteine metabolism-related enzymes and the associated factors in isolated systolic hypertension. Chin J Cardiol 2003; 31: 269-273.

16 Wang S, Shen R, Shi X et al: The role of homocysteine metabolism related enzymes gene polymorphisms on pregnancy-induced hypertension. Chin J Prep Genet 2006; 14: 15-17.

17 Gao Y, Zhan S, Yin X, Hu Y, Li L: The relationship between methylenetetrahydrofolate reductase polymorphism and risk of essential hypertension. J Beijing Med Univ 1999; 31: 370-371.

18 Zhan S, Gao Y, Yin X et al: Elevated serum homocystein, MTHFR gene mutation and essential hypertension in Chinese. Chin J Hypertens 2000; 8: 21-25.

19 Li K, Sun Y, Chen L, Zhang G, Li P: Study on the relationship between methylenetetrahydrofolate reductase gene polymorphism and plasma homocysteine level in pregnancy induced hypertension patients. Chin J Obstet Gynecol 2000; 35: 205-207.

20 Wang L, Guo H, Li Y: MTHFR Gene C 677 T polymorphisms and variation of plasma homocysteine levels. Tianjin Med J 2002; 30: $579-582$.

21 Li X, Huang W: The analysis of MTHFR gene polymorphism in patients with renal damage caused by hypertension and patients with renal parenchymal hypertension. J Capital Univ Med Sci 2006; 27: 497-500.

22 Liu J, Ye L, Liu J, Li X: Study on homocysteine metabolism related enzymes gene polymorphisms in elderly essential hypertension patients with peripheral arterial occlusive disease. Chin J Geriatr 2005; 24: 332-335.

23 Tian G, She D, Qi Q: Genetic research between gene polymorphisms of homocysteine metabolism- related enzymes and preeclampsia. Thromb Hemost 2005; 11: 197-199.

24 Mao D, Li K, Zhao Y: Study on MTHFR gene and ACE gene polymorphisms in pregnancy-induced hypertension. Chin J Perinat Med 2004; 7: 22-24.

25 Liu J, Ye L, Liu J, Li X: Methylenetetrahydrofolate reductase gene polymorphism and susceptibility to peripheral arterial occlusive disease in hypertensive patients. Chin J Geriatr Heart Brain Vessel Dis 2004; 6: 4-6. 
$26 \mathrm{Fu} \mathrm{F}$, Liu H, Liao D et al: Investigation of the relationship between polymorphism of methylenetetrahydofolate reductase and pregnancy induced hypertension syndrome. Chin J Jiangxi Med 2003; 38: 401-403.

27 Wei S, Zheng J, Shi D, Zou L, Bi L: Relationship between pregnancy induced hypertension and the polymorphisms of MTHFR gene and plasma homocysteine levels. China J Mod Med 2001; 11: 10-19.

28 Lwin H, Yokoyama $\mathrm{T}$, Yoshiike $\mathrm{N}$ et al: Polymorphism of methylenetetrahydrofolate reductase gene (C677T MTHFR) is not a confounding factor of the relationship between serum uric acid level and the prevalence of hypertension in Japanese men. Circ J 2006; 70: 83-87.

29 Kobashi G: Genetic and environmental factors associated with the development of hypertension in pregnancy. J Epidemiol 2006; 16: $1-8$.

30 Tylicki L, Födinger M, Puttinger $\mathrm{H}$ et al: Methylenetetrahydrofolate reductase gene polymorphisms in essential hypertension. Am J Hyper 2005; 18: 1442-1448.

31 Heux S, Morin F, Lea RA, Ovcaric M, Tajouri L, Griffiths LR: The methylenetetrahydrofolate reductase gene variant $(\mathrm{c} 677 \mathrm{t})$ as a risk factor for essential hypertension in Caucasians. Hypertens Res 2004; 27: 663-667.

32 Yilmaz H, Unlucerci Y, Gurdol F, Isbilen E, Isbir T: Association of pre-eclampsia with hyperhomocysteinaemia and methylenetetrahydrofolate reductase gene C677T polymorphism in a Turkish population. Aust NZJ Obstet Gynaecol 2004; 44: 423-427.

33 Benes P, Kankova K, Muzik J et al: Methylenetetrahydrofolate reductase polymorphism, type II diabetes mellitus, coronary artery disease, and essential hypertension in the Czech population. Mol Genet Metab 2001; 73: 188-195.

34 Nakata Y, Katsuya T, Takami S et al: Methylenetetrahydrofolate reductase gene polymorphism: relation to blood pressure and cerebrovascular disease. Am J Hypertens 1998; 11: 1019-1023.

35 Kobashi G, Yamada H, Asano T et al: Absence of association between a common mutation in the methylenetetrahydrofolate reductase gene and preeclampsia in Japanese women. Am J Med Genet 2000; 93: 122-125.
36 Nagy B, Hupuczi P, Papp Z: High frequency of methylenetetrahydrofolate reductase 677TT genotype in Hungarian HELLP syndrome patients determined by quantitative real-time PCR. J Hum Hypertens 2007; 21: 154-158.

37 Hernandez-Diaz S, Wu XF, Hayes C et al: Methylenetetrahydrofolate reductase polymorphisms and the risk of gestational hypertension. Epidemiology 2005; 16: 628-634.

38 Powers RW, Minich LA, Lykins DL, Ness RB, Crombleholme WR, Roberts JM: Methylenetetrahydrofolate reductase polymorphism, folate, and susceptibility to preeclampsia. J Soc Gynecol Invest 1999; 6: 74-79.

39 Grandone E, Margaglione M, Colaizzo D et al: Prothrombotic genetic risk factors and the occurrence of gestational hypertension with or without proteinuria. Thromb Haemost 1999; 81: 349-352.

40 Ioannidis JP: Effect of the statistical significance of results on the time to completion and publication of randomized efficacy trial. JAMA 1998; 279: 281-286.

41 Easterbrook PJ, Berlin JA, Gopalan R, Matthews DR: Publication bias in clinical research. Lancet 1991; 337: 867-872.

42 Dickersin K, Min YI, Meinert CL: Factors influencing publication of research results. Follow-up of applications submitted to two institutional review boards. JAMA 1992; 267: 374-378.

43 Kosmas IP, Tatsioni A, Ioannidis JP: Association of C677T polymorphism in the methylenetetrahydrofolate reductase gene with hypertension in pregnancy and pre-eclampsia: a metaanalysis. J Hypertens 2004; 22: 1655-1662.

44 De Wolf F, Brosens I, Renaer M: Fetal growth retardation and the maternal arterial supply of the human placenta in the absence of sustained hypertension. Br J Obstet Gynaecol 1980; 87: 678-685.

45 Redman CW: Current topic: pre-eclampsia and the placenta. Placenta 1991; 12: 301-308.

46 Roberts JM, Taylor RN, Goldfien A: Clinical and biochemical evidence of endothelial cell dysfunction in the pregnancy syndrome preeclampsia. Am J Hypertens 1991; 4: 700-708.

47 Stehouwer CD, van Guldener C: Does homocysteine cause hypertension? Clin Chem Lab Med 2003; 41: 1408-1411. 